\title{
Mental health stigma: another enemy for defeat chronic pain
}

Department of Anesthesiology and Pain Medicine, Soonchunhayng University Bucheon Hospital, Bucheon, Korea

Joon Ho Lee

Chronic pain is associated with several types of psychiatric problems. Among these conditions, depression is one of the most commonly coexisting and investigated problems. Although there is still debate on "which came first, the chicken or the egg", it is true that over the half of chronic pain patients present a depressed condition and over half of depressed patients report pain [1].

As with other disease, early interventions to this comorbidity could obviously have a significant impact on disease prognosis. The severity of pain is correlated with the severity of depression and its resistance to treatment. Also, neglected depression itself hinders the patients' will to rehabilitate, and inhibit breaking out of the vicious circle of pain and disability $[2,3]$.

However, in Korea, the entry barrier to meeting a psychiatrist is still high, not because of prejudices towards mental illness among patients, but because of the ignorance of some doctors who treat pain. Things have improved a lot in recent years, but still only fewer than half of the patients who were diagnosed with a mental illness are treated [4]. Most chronic pain patients who are counseled to receive mental support do not yet want to go to a psychiatric clinic. So in my case, I've had to become an unofficial psychiatrist, because my patients also do not want to visit a real one, no matter how much I urge them. Actually, social stigma regarding mental illness is a world- wide problem these days. What's even worse, there are no validated screening tools for comorbid pain and depression [5].

Moreover, the fact that the improvement of depression does not directly improve pain makes clinicians hesitate to give good advice about mental health care [3].

In this issue of The Korean journal of Pain, Lee et al. [6] present an article about the prevalence of unrecognized depression in chronic pain patients. To my knowledge, it is the first report about the prevalence of depression in chronic pain patients in Korea from the clinicians' point of view. Even if it is just a single center study, I hope this research can be a start in letting Korean people know how many chronic pain patients are suffering from depression. And I'm looking forward future multi-center studies with excitement.

\section{REFERENCES}

1. Surah A, Baranidharan G, Morley S. Chronic pain and depression. Contin Educ Anaesth Crit Care Pain 2014; 14: 85-9.

2. Bair MJ, Robinson RL, Katon W, Kroenke K. Depression and pain comorbidity: a literature review. Arch Intern Med 2003; 163: 2433-45.

3. Gureje O. Treating chronic pain in the context of comorbid depression. Pain 2008; 134: 3-4.

Received March 15, 2018. Revised March 17, 2018. Accepted March 20, 2018.

Correspondence to: Joon Ho Lee

Department of Anesthesiology and Pain Medicine, Soonchunhayng University Bucheon Hospital, 1174 Jung-dong, Bucheon 14584, Korea Tel: +82-32-621-5340, Fax: +82-32-621-5322, E-mail: anpjuno@schmc.ac.kr

(c) This is an open-access article distributed under the terms of the Creative Commons Attribution Non-Commercial License (http:// creativecommons.org/licenses/by-nc/4.0/), which permits unrestricted non-commercial use, distribution, and reproduction in any medium, provided the original work is properly cited.

Copyright (c) The Korean Pain Society, 2018 
72 || Korean J Pain Vol. 31, No. 2, 2018

4. Park JI, Jeon M. The stigma of mental illness in Korea. J Korean Neuropsychiatr Assoc 2016; 55: 299-309.

5. Cocksedge K, Shankar R, Simon C. Depression and pain: the need for a new screening tool. Prog Neurol Psychiatry 2016; 20: 26-32.
6. Lee HJ, Choi EJ, Nahm FS, Yoon IY, Lee PB. Prevalence of unrecognized depression in patients with chronic pain without a history of psychiatric diseases. Korean $J$ Pain 2018; 31: 116-24. 